\title{
Cyclodextrin-based catalysts and molecular reactors*
}

\author{
Christopher J. Easton \\ Research School of Chemistry, Australian National University, Canberra ACT 0200, \\ Australia
}

\begin{abstract}
The naturally occurring cyclodextrins and their derivatives have been developed as miniature reaction vessels, to manipulate the outcomes of chemical transformations at the molecular level. In this manner, the rate of hydrolysis of a phosphate triester has been enhanced by almost five orders of magnitude, and the ratios of products obtained from electrophilic aromatic substitution reactions, from competing reactions to give indigoid dyes, and from nitrile oxide cycloadditions have all been changed, by factors of up to 3500 times.
\end{abstract}

Keywords: Cyclodextrins; molecular reactors; catalysts; templates; reaction control.

Molecular reactors are miniature reaction vessels that control the assembly of reagents to affect the outcomes of chemical transformations at the molecular level [1]. In many ways, they are analogous to the reaction vats used in chemical industry, the flasks used in chemical laboratories, and even the cooking pots used in kitchens. In each case, containers are used to bring together the required ingredients. After the chemical reactions have taken place, sometimes as a result of stirring or heating, the products are removed and the containers may be reused. The unique aspect of molecular reactors is that they act at the molecular level, and it is implicit that this changes the outcomes of the reactions, to make them different from those that would result when using bulk reaction media, such as common solvents. Where molecular reactors act in this manner, without themselves being altered, by definition they are operating as catalysts.

The starting materials we use to develop molecular reactors are the naturally occurring cyclodextrins 1-3 (Fig. 1). These cyclic oligosaccharides have been known for more than a century [2], and they are now also used extensively in the pharmaceutical industry [3], in household and personal care products [4], and as food additives [5]. All these applications are related to the shape and consequent properties of the cyclodextrins 1-3. Their shape resembles a truncated cone (Fig. 1) or may be visualized as being similar to a donut. Their exterior surfaces are hydrophilic due to the presence of the hydroxyl groups, while the annulus of the cone or hole in the middle of the donut is hydrophobic, being surrounded by carbon-hydrogen bonds and ether linkages. As a result, in aqueous solution, cyclodextrins form inclusion complexes with hydrophobic guests (Scheme 1).

\footnotetext{
*Paper based on a presentation at the $17^{\text {th }}$ International Conference on Physical Organic Chemistry (ICPOC-17), Shanghai, China, 15-20 August 2004. Other presentations are published in this issue, pp. 1807-1921.
} 

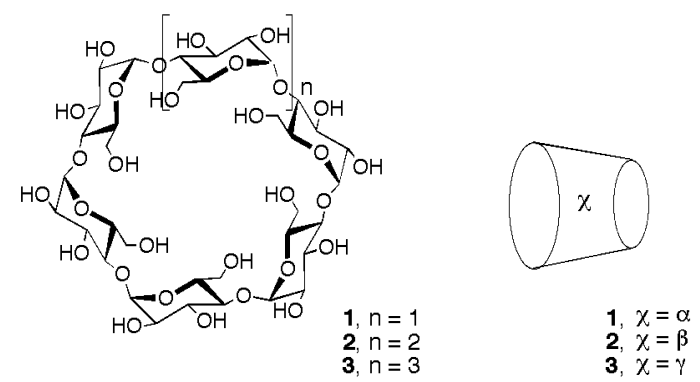

Fig. 1 The structures and truncated cone representation of the naturally occurring cyclodextrins 1-3. A substituent drawn at the narrow end of the cone indicates that it replaces one of the primary hydroxyl groups.

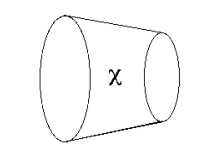

Cyclodextrin Host
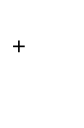

Hydrophobic

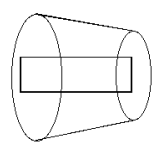

Inclusion Complex

Scheme 1

In a simple example of the use of cyclodextrins as molecular reactors taken from our own work, but which is derivative of earlier studies by Breslow et al. [6-8], and other groups [9-11], of the effect of cyclodextrins on electrophilic aromatic substitution reactions, each of the native cyclodextrins $\mathbf{1}$ and $\mathbf{2}$ affects the regioselectivity of bromination of acetanilide $\mathbf{4}$ and anisole $\mathbf{7}$ with pyridinium dichlorobromate (Scheme 2) [12]. In the absence of a cyclodextrin, acetanilide 4 reacts to give a 56:44 mixture of the para- and ortho-brominated compounds $\mathbf{5}$ and $\mathbf{6}$. The ratio of these products is changed to 79:21 when the reaction is carried out in the presence of $\beta$-cyclodextrin $\mathbf{2}$, whereas the use of $\alpha$-cyclodextrin 1 results in the formation of 4-bromoacetanilide $\mathbf{5}$ as the only detectable product. Similar results are observed with the bromination of anisole $\mathbf{7}$. These effects may be attributed to the cyclodextrins $\mathbf{1}$ and $\mathbf{2}$ acting as molecular reactors, by including acetanilide $\mathbf{4}$ and anisole $\mathbf{7}$ in the orientation shown in Fig. 2, whereby their ortho positions are shielded from reaction, while their para positions remain accessible to the brominating agent.

The bromination of 3-methylanisole $\mathbf{1 0}$ is unusual in that the monobromide $\mathbf{1 1}$ is more reactive than the starting material (i.e., the bromo group activates the system toward electrophilic aromatic substitution), so subsequent reactions occur to produce the dibromides 12 and $\mathbf{1 3}$ (Scheme 2) [12]. In this case, the cyclodextrins 1 and 2 restrict the extent of formation of the dibromides 12 and 13, with $\beta$-cyclodextrin 2 having the greatest effect.

In terms of providing a method for the synthesis of the para-brominated products $\mathbf{5}$ and $\mathbf{8}$, and the monobromide 11, an obvious advantage of using the cyclodextrins $\mathbf{1}$ and $\mathbf{2}$ is to increase the yields. Just as importantly, the quantities of the corresponding reaction by-products are reduced and product isolation becomes more straightforward, particularly through the use of $\alpha$-cyclodextrin $\mathbf{1}$ with acetanilide $\mathbf{4}$ where there is no need to separate product isomers. An added bonus from using the cyclodextrins $\mathbf{1}$ and $\mathbf{2}$ is that they increase the solubility of the substrates $\mathbf{4 , 7}$, and $\mathbf{1 0}$ in water, making it practical to use this as a cheap and environmentally benign alternative to the organic solvents commonly used for such transformations. The aqueous cyclodextrin solutions can also be used repeatedly, in batch-style processes, by adding the reactants, allowing the reactions to proceed before extracting the products with organic solvents, and then repeating these steps.

While the methods described above represent very efficient procedures for selectively producing the bromides $\mathbf{5}, \mathbf{8}$, and 11, these effects of the cyclodextrins $\mathbf{1}$ and $\mathbf{2}$ are due to a somewhat fortuitous self-assembly of the reagents. However, by modifying the cyclodextrins $\mathbf{1}-\mathbf{3}$, it is also possible to con- 


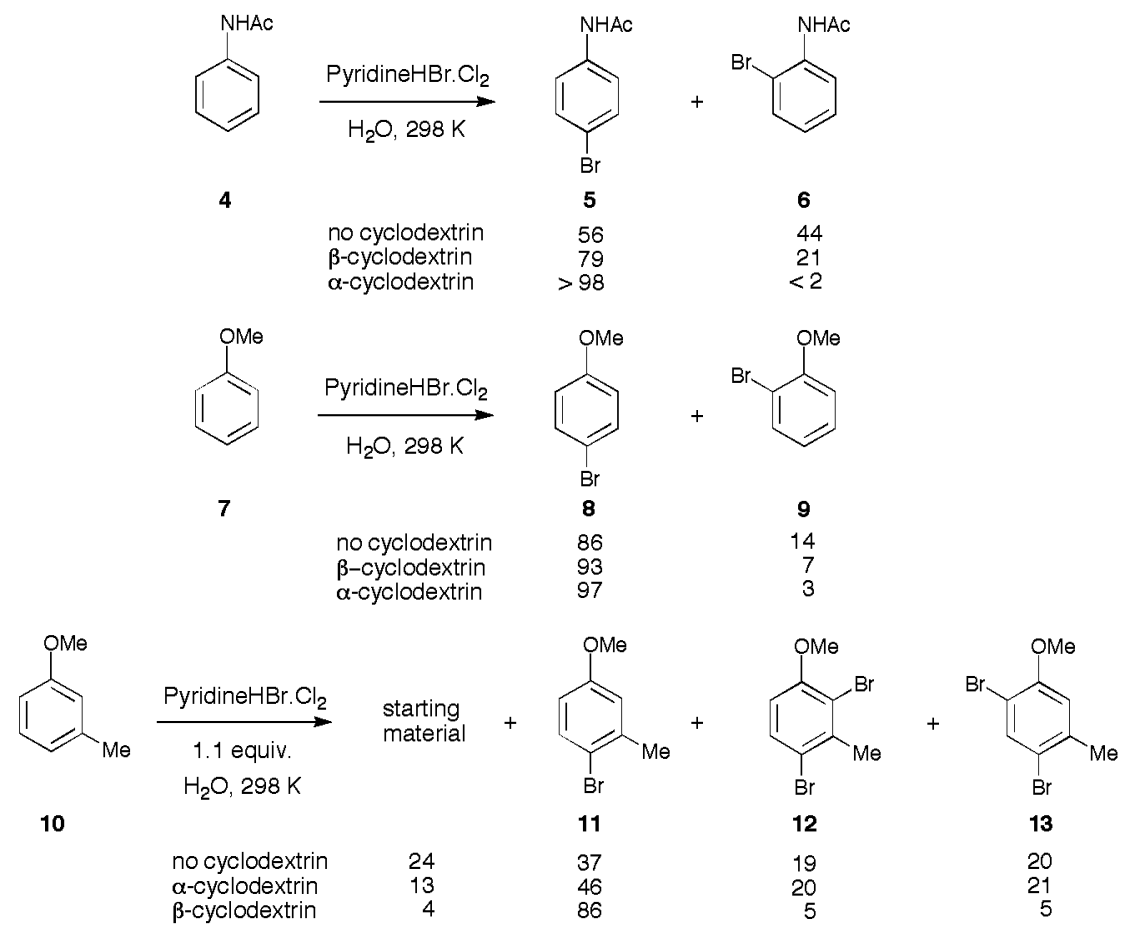

Scheme 2

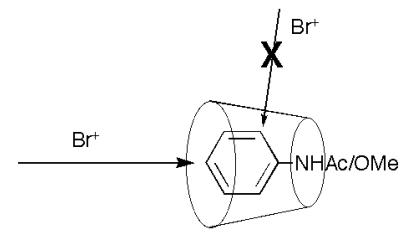

Fig. 2 Effect of the cyclodextrins 1 and $\mathbf{2}$ in blocking access of a brominating agent to the ortho positions of acetanilide $\mathbf{4}$ and anisole $\mathbf{7 .}$

trol the assembly of reagents, in order to manipulate the outcomes of chemical reactions by design. In this regard, the cyclodextrins 1-3 are being used as scaffolds and templates for the construction of molecular reactors [13].

Again, to use an example from our own work, which is illustrated in Scheme 3, the complex of $6^{\mathrm{A}}$-(3-aminopropylamino)- $6^{\mathrm{A}}$-deoxy- $\beta$-cyclodextrin with $\mathrm{Cu}^{\mathrm{II}} 15$ catalyzes the hydrolysis of the organophosphate triester 14 [14]. In aqueous $0.05 \mathrm{~mol} \mathrm{dm}^{-3}$ HEPES buffer at $\mathrm{pH} 7.0$ and $298 \mathrm{~K}$, the interaction of the triester $\mathbf{1 4}$ with the metallocyclodextrin $\mathbf{1 5}$ is characterized by an association constant for the formation of the ternary complex 16 of $235 \mathrm{~mol}^{-1} \mathrm{dm}^{3}$, and a pseudo-first-order rate constant for reaction of the included species $\left(k_{\text {inc }}\right)$ of $3.1 \times 10^{-2} \mathrm{~s}^{-1}$. By comparison, under the same conditions, the pseudo-first-order rate constant for the uncatalyzed hydrolysis of the triester $\mathbf{1 4}\left(k_{\mathrm{un}}\right)$ is $3.2 \times 10^{-7} \mathrm{~s}^{-1}$. On this basis, the metallocyclodextrin 15 accelerates the rate of hydrolysis of the triester $14\left(k_{\text {inc }} / k_{\text {un }}\right)$ by 97000 times. The metallocyclodextrin 15 is a true catalyst, in that multiple turnover of the substrate $\mathbf{1 4}$ is observed. Water bound to copper in the metallocyclodextrin $\mathbf{1 5}$ has a $\mathrm{p} K_{\mathrm{a}}$ of 7.84 [15], and the hydrolysis at $\mathrm{pH} 7.0$ is most probably brought about by the corresponding hydroxide.

The reaction of the triester $\mathbf{1 4}$ catalyzed by the metallocyclodextrin $\mathbf{1 5}$ is a hydrolytic process. Cyclodextrin-based molecular reactors have also been developed to control the outcomes of 


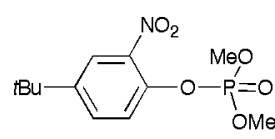

14

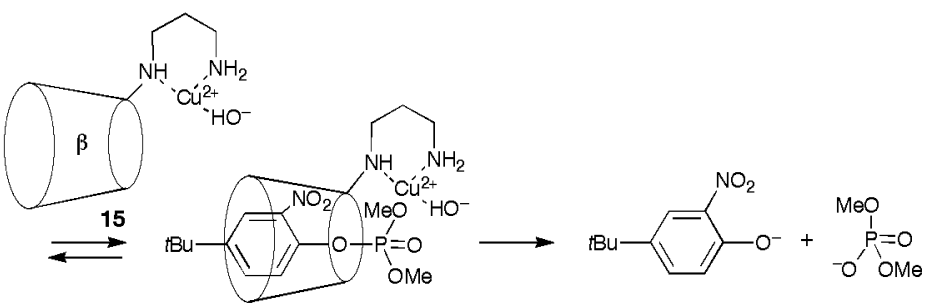

16

Scheme 3

carbon-carbon bond-forming reactions and to affect the regioselectivity of incorporation of functional groups. Breslow's group has been especially active in these areas [16,17], and, in particular, they have reported some quite advanced systems for the controlled hydroxylation of steroids [16].

We have exploited cyclodextrin dimers to bias competing reactions of indoxyl 18 and isatin 19a to give indigoid dyes (Scheme 4) [18]. In aqueous solution at $\mathrm{pH}$ 10.0, indoxyl acetate $\mathbf{1 7}$ hydrolyzes to indoxyl 18, which can either oxidize to isatin 19a or undergo oxidative dimerization to give indigo 20. Indoxyl 18 also reacts with isatin 19a to give indirubin 21a. From studies of the cooperative binding of dyes by cyclodextrin dimers [19], it was apparent that the urea derivative $\mathbf{2 2}$ more readily adopted the conformation of indirubin 21a than that of indigo 20, and it was therefore anticipated that it would favor the reaction of indoxyl 18 with isatin 19a. Accordingly, under conditions where in the absence of a cyclodextrin indoxyl 18 and isatin 19a reacted to give a mixture of indigo 20 and indirubin $21 \mathrm{a}$ in yields of 16 and $13 \%$, respectively, in the presence of the cyclodextrin dimer $\mathbf{2 2}$, the yields of indigo 20 and indirubin 21 a were 0.03 and $1.0 \%$. Thus, the cyclodextrin 22 changed the ratio of formation of the dyes 20 and 21a by a factor of approximately 40 .

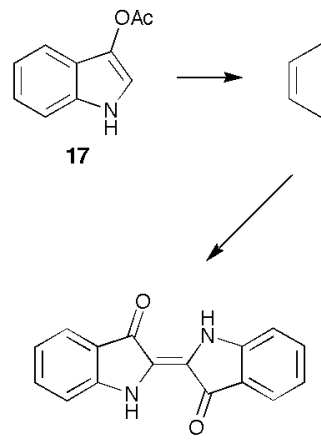

20<smiles>Oc1c[nH]c2ccccc12</smiles>

18<smiles>[X]c1ccc2c(c1)C(=O)C(=O)N2</smiles>

19 a $X=H$

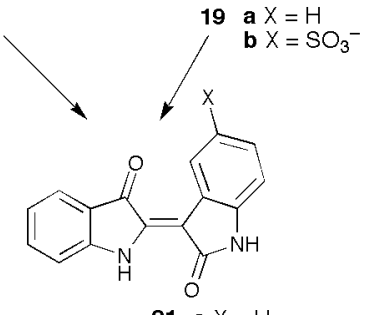

21 a $X=\mathrm{H}$ b $\mathrm{X}=\mathrm{SO}_{3}-$

Scheme 4

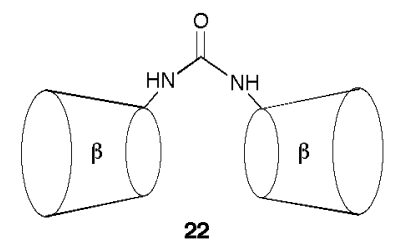

Presenting this material in lectures provides an opportunity to assess how much the audience are paying attention. If there is no sniggering or interruption at this point, they are either asleep or too polite to point out that the ratio of the dyes $\mathbf{2 0}$ and 21a has only been changed by reducing their combined 
yield by a factor of almost 30 and the yield of indirubin 21a by 13 times. It is difficult to argue that the use of the cyclodextrin dimer $\mathbf{2 2}$ in this system constitutes a real practical advantage!

This effect of the cyclodextrin $\mathbf{2 2}$ to reduce the yields of the dyes $\mathbf{2 0}$ and $\mathbf{2 1 a}$ is a consequence of the complexation of indoxyl 18 and isatin 19a increasing their effective steric bulk and reducing the frequency of their productive collisions. This is likely to be a common effect associated with the use of molecular reactors, but it can be addressed by developing systems where the reactivity of the reagents is actually increased as a result of their inclusion. In this particular example, this was achieved through the use of the isatinsulfonate 19b instead of isatin 19a. In aqueous solution, the sulfonate $19 \mathrm{~b}$ is in equilibrium with the corresponding hydrate, which deprotonates with a $\mathrm{p} K_{\mathrm{a}}$ of 9.55 . The cyclodextrin complexes the sulfonate $19 \mathrm{~b}$ in preference to both the hydrate and the anion, to increase the $\mathrm{p} K_{\mathrm{a}}$ of the hydrate and decrease the extent of hydration of the complexed isatinsulfonate $\mathbf{1 9 b}$. More of the material is therefore present as the sulfonate $19 \mathrm{~b}$ when it is complexed, and since this is the form that reacts with indoxyl 18, this reactivity is increased. As a result, under conditions where in the absence of a cyclodextrin indoxyl 18 and the isatinsulfonate $19 \mathrm{~b}$ reacted to give a mixture of indigo 20 and the indirubinsulfonate $\mathbf{2 1 b}$ in yields of 25 and $1.4 \%$, respectively, in the presence of the cyclodextrin dimer 22 the yields of indigo $\mathbf{2 0}$ and the indirubinsulfonate $\mathbf{2 1 b}$ were $<0.1$ and $22 \%$. In this case, the cyclodextrin $\mathbf{2 2}$ changed the ratio of formation of the dyes $\mathbf{2 0}$ and $\mathbf{2 1 b}$ by a factor of at least 3500 , without any decrease in yield.

We have also developed cyclodextrin-based molecular reactors to reverse the regioselectivity of nitrile oxide cycloadditions [20-22]. Nitrile oxides (dipoles) react with alkynes and alkenes (dipolarophiles) to give isoxazoles and isoxazolines, respectively. With mono-substituted dipolarophiles, there exists the possibility of formation of regioisomeric mixtures of products, but in practice it is almost invariably found that, in these systems, the 5-substituted cycloadducts predominate (Scheme 5) [23]. However, by using $\beta$-cyclodextrin 2 as a molecular scaffold, it has been possible to change the outcome. Tethering the dipolarophiles to the cyclodextrin and then allowing preassociation of the modified cyclodextrins with aromatic nitrile oxides, as host-guest complexes, controls the relative orientation of the dipoles and dipolarophiles, to afford primarily 4-substituted isoxazoles and isoxazolines (Scheme 6).

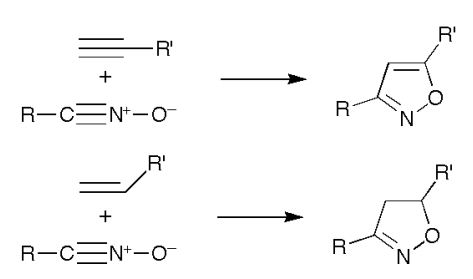

Scheme 5

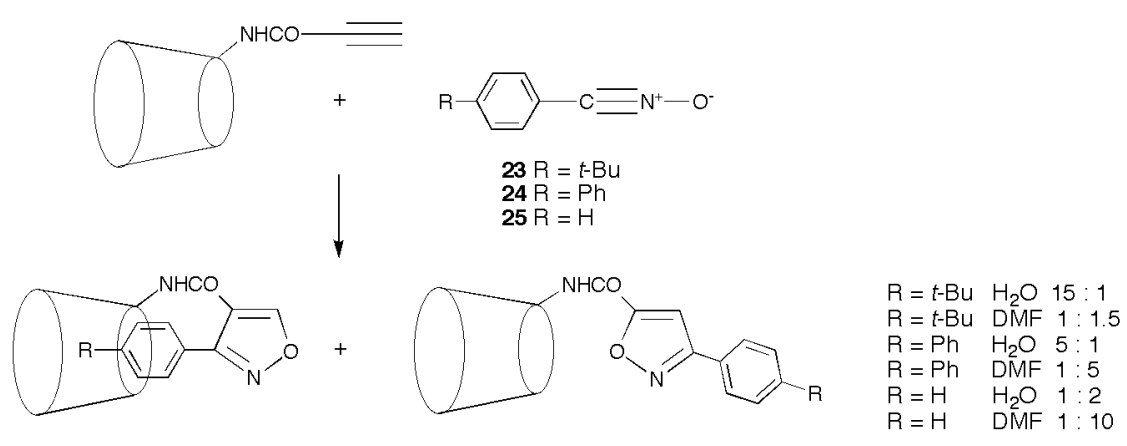

Scheme 6 
The magnitude of the reversal of the regioselectivity depends on the extent of complexation of the nitrile oxide by the cyclodextrin. As a result, the effect is greater with the tert-butylphenyl- and biphenyl-nitrile oxides $\mathbf{2 3}$ and $\mathbf{2 4}$, than with phenylnitrile oxide $\mathbf{2 5}$, and less when the reactions are carried out in $\mathrm{N}, \mathrm{N}$-dimethylformamide rather than water, because complexation is disfavored by the former.

Thus, cyclodextrins can be used as scaffolds and templates, to design and build molecular reaction vessels, in order to manipulate the outcomes of chemical transformations at the molecular level. Product ratios may be substantially changed, and reaction rates may be significantly increased. In addition, the molecular reactors work most efficiently in water, often at room temperature and near neutral $\mathrm{pH}$, so this makes them attractive for use both in the laboratory and in chemical industry.

\section{ACKNOWLEDGMENTS}

The author gratefully acknowledges the support of the Australian Research Council and the contributions of an enthusiastic group of coworkers. Individual contributions are noted in the references.

\section{REFERENCES}

1. C. J. Easton, S. F. Lincoln, L. Barr, H. Onagi. Chem. Eur. J. 10, 3120 (2004).

2. (a) A. Villiers. Compt. Rend. 112, 536 (1891); (b) F. Z. Schardinger. Unters. Nahr. u. genussm. 6, 865 (1903); (c) F. Z. Schardinger. Wien. Klin. Wochenscht. 17, 207 (1904); (d) F. Z. Schardinger. Zentralbl. Bakteriol. Parasintenk. Abt. 2 14, 772 (1905); (e) F. Z. Schardinger. Zentralbl. Bakteriol. Parasintenk. Abt. 2 29, 118 (1911).

3. (a) H. Arima, F. Hirayama, C. T. Okamoto, K. Uekama. Recent Res. Dev. Chem. Pharm. Sci. 2, 155 (2002); (b) M. K. Chourasia and S. K. Jain. Drug Delivery 11, 129 (2004).

4. L. Povoa and H. Cabral Marques. Rev. Port. Farm. 51, 139 (2001).

5. (a) J. Szejtli. Chem. Rev. 98, 1743 (1998); (b) J. Szejtli. Enycl. Nanosci. Nanotechnol. 2, 283 (2004).

6. R. Breslow and P. Campbell. J. Am. Chem. Soc. 91, 3085 (1969).

7. R. Breslow and P. Campbell. Bioorg. Chem. 1, 140 (1971).

8. R. Breslow, H. Kohn, B. Siegel. Tetrahedron Lett. 1645 (1976).

9. R. Chênevert and G. Ampleman. Can. J. Chem. 65, 307 (1987).

10. M. Komiyama and H. Hirai. J. Am. Chem. Soc. 105, 2018 (1983).

11. M. Komiyama and H. Hirai. J. Am. Chem. Soc. 106, 174 (1984).

12. P. G. Dumanski, C. J. Easton, S. F. Lincoln, J. S. Simpson. Aust. J. Chem. 56, 1107 (2003).

13. C. J. Easton and S. F. Lincoln. Modified Cyclodextrins. Scaffolds and Templates for Supramolecular Chemistry, Imperial College Press, London (1999).

14. L. Barr, C. J. Easton, K. Lee, S. F. Lincoln, J. S. Simpson. Tetrahedron Lett. 43, 7797 (2002).

15. (a) S. E. Brown, J. H. Coates, C. J. Easton, S. F. Lincoln. J. Chem. Soc., Faraday Trans. 90, 739 (1994); (b) S. E. Brown, J. H. Coates, C. J. Easton, S. J. van Eyk, S. F. Lincoln, B. L. May, M. A. Stile, C. B. Whalland, M. L. Williams. J. Chem. Soc., Chem. Commun. 47 (1994); (c) S. E. Brown, C. A. Haskard, C. J. Easton, S. F. Lincoln. J. Chem. Soc., Faraday Trans. 91, 1013 (1995); (d) C. A. Haskard, C. J. Easton, B. L. May, S. F. Lincoln. Inorg. Chem. 35, 1059 (1996).

16. (a) J. Yang and R. Breslow. Angew. Chem., Int. Ed. Engl. 39, 2692 (2000); (b) J. Yang, B. Gabriele, S. Belvedere, Y. Huang, R. Breslow. J. Org. Chem. 67, 5057 (2002).

17. (a) J. M. Desper and R. Breslow, J. Am. Chem. Soc. 116, 12081 (1994); (b) R. Breslow. Acc. Chem. Res. 28, 146 (1995); (c) W. Weiner, J. Winkler, S. C. Zimmerman, A. W. Czarnik, R. Breslow. J. Am. Chem. Soc. 107, 4093 (1985).

18. (a) J. B. Harper, C. J. Easton, S. F. Lincoln. Tetrahedron Lett. 44, 5815 (2003); (b) C. J. Easton, J. B. Harper, S. F. Lincoln. New J. Chem. 22, 1163 (1998). 
19. (a) C. A. Haskard, B. L. May, T. Kurucsev, S. F. Lincoln, C. J. Easton. J. Chem. Soc., Faraday Trans. 93, 279 (1997).

20. A. G. Meyer, C. J. Easton, S. F. Lincoln, G. W. Simpson. Chem. Commun. 1517 (1997).

21. A. G. Meyer, C. J. Easton, S. F. Lincoln, G. W. Simpson. Org. Chem. 63, 9069 (1998).

22. L. Barr and C. J. Easton. Unpublished results.

23. C. J. Easton, C. M. M. Hughes, G. P. Savage, G. W. Simpson. Adv. Heterocycl. Chem. 60, 261 (1994). 